\title{
As Regiões Metropolitanas no Brasil e o problema Institucional de Cooperação: a trajetória das Regiões Metropolitanas de Natal e Aracaju
}

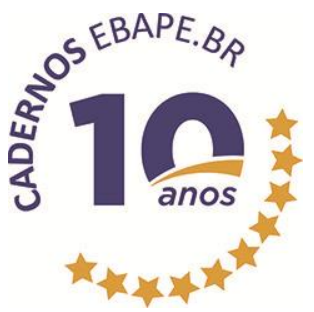

\author{
Metropolitan areas in Brazil and the Institutional problem of Cooperation: the path of the \\ metropolitan areas from Natal and Aracaju
}

\author{
Diego Fiel Santos1 \\ Antônio Sérgio Araújo Fernandes2 \\ Marco Antonio Carvalho Teixeira ${ }^{3}$
}

\section{Resumo}

O trabalho analisa a evolução do processo de institucionalização das Regiões Metropolitanas brasileiras, tendo como objeto empírico os casos de Natal-RN e Aracaju-SE. Por meio da análise institucional histórica e comparada sobre a constituição dos arranjos normativos das Regiões Metropolitanas de Aracaju e Natal, busca-se compreender como se deu o processo de formação, cooperação na gestão das áreas metropolitanas analisadas. Apesar dos diferentes contextos específicos respectivos de cada Região Metropolitana, observa-se como característica comum em ambas que não existem mecanismos institucionais e de cooperação tanto Federativos quanto intrametropolitanos que incentivem o interesse por parte dos entes federados para a cooperação. Ainda que exista uma frágil motivação política nos dois casos analisados, estes mostram uma baixa institucionalização, o que caracteriza estas duas regiões metropolitanas como um quadro de cooperação incipiente tornando inviável avançar em termos de gestão metropolitana.

Palavras-chave: Gestão Metropolitana. Teoria Institucional. Ação Coletiva.

\section{Abstract}

The paper analyzes the evolution of the process of institutionalization of Brazilian metropolitan areas, where the object of empirical cases Natal-RN and Aracaju-SE. Through historical and comparative institutional analysis on the constitution of regulatory arrangements of the metropolitan areas of Natal and Aracaju, seeks to understand how was the process of

Artigo submetido em 28 de abril de 2013 e aceito para publicação em 16 de setembro de 2013.

Gostaríamos de agradecer imensamente aos avaliadores do Cadernos EBAPE.BR que apreciaram o artigo, pelas relevantes críticas, comentários e sugestões que fizeram o texto melhorar sobremaneira. Sem a leitura atenta e rigorosa destes pareceristas não teríamos condição de observar elementos que constituíam lacunas e imprecisões importantes no trabalho. Evidentemente que quaisquer erros e falhas ainda contidas no artigo são de inteira responsabilidade dos autores.

${ }^{1}$ Mestre em Administração pela Universidade Federal do Rio Grande do Norte; Professor Assistente A do Departamento de Ciências Administrativas da Universidade Federal de Juiz de Fora - Campus Governador Valadares - MG. Endereço: Campus Governador Valadares - UFJF, Avenida Doutor Raimundo Monteiro Resende, 330, Centro, CEP 35000-000, Governador Valadares - MG, Brasil. E-mail: diego.fiel@ufjf.edu.br

${ }^{2}$ Doutor em Ciência Política pela Universidade de São Paulo com Pós-Doutoramento em Administração Pública pela University of Texas at Austin; Professor adjunto 4 do Programa de Pós-Graduação em Administração da Universidade Federal do Rio Grande do Norte. Endereço: UFRN - Programa de Pós-Graduação em Administração, Ed. do Centro de Ciências Sociais Aplicadas, Campus Universitário, Lagoa Nova, Caixa Postal 1620, CEP 59072-970, Natal - RN, Brasil. E-mail: antoniosergio07@gmail.com

${ }^{3}$ Dou

Doutor em Ciências Sociais pela PUC-SP; Professor do Departamento de Gestão Pública da Fundação Getulio Vargas de São Paulo, onde é vice-coordenador da graduação em Administração Pública. Endereço: FGV/EAESP - Escola de Administração de Empresas da Fundação Getulio Vargas, Avenida Nove de Julho, 2029, 3ํandar, Bela Vista, CEP 01313-902, São Paulo - SP, Brasil. E-mail: marco.teixeira@fgv.br 
training, cooperation in the management of metropolitan areas analyzed. Despite their different specific contexts of each metropolitan area, there is a common characteristic in both there are no institutional mechanisms and cooperation so as Federated intrametropolitan that encourage interest from federal agencies for cooperation. Although there is a fragile political motivation in both cases analyzed, they show a low institutionalization, which characterizes these two metropolitan areas as a framework for cooperation incipient making it impossible to advance in terms of metropolitan management.

Keywords: Metropolitan Management. Institutional Theory. Collective Action.

\section{Introdução}

A gestão metropolitana continua sendo um tema de ampla complexidade tanto no ambiente acadêmico quanto no campo político. Os territórios metropolitanos são espaços que apresentam mais claramente os conflitos existentes no pacto federativo brasileiro. A partir da Constituição Brasileira de 1988, as Regiões Metropolitanas (RMs) passaram a ser competência de institucionalização estadual. Entretanto a constituição das mesmas não estabelece meios coercitivos para formação e definição desses territórios.

Nesse contexto, o presente trabalho buscou compreender quais são as condicionantes para a efetiva gestão das RMs no território brasileiro. Através de uma análise dos aspectos institucionais legais sobre os territórios metropolitanos, foi realizada uma análise comparada entre as Regiões Metropolitanas de Natal e Aracaju. Estas duas localidades foram escolhidas por terem sido criadas após a Constituição Brasileira de 1988, na década de 1990 , e também pela facilidade de acesso a dados e a atores que participaram do processo de construção das duas experiências.

De caráter exploratório, essa pesquisa buscou na reconstrução da trajetória dos dois casos, compreender suas particularidades e contribuir para a reflexão sobre as dificuldades no desenvolvimento de arranjos cooperativos intergovernamentais no Brasil, como ênfase no caso dessas Regiões Metropolitanas. Portanto, esse trabalho não tem a intenção de comparar as duas experiências e, muito menos, avaliar o desempenho de ambas. Para a realização deste

trabalho, foram consultadas legislações dos dois estados, atas de reuniões nas respectivas assembleias legislativas e nos respectivos conselhos e fóruns onde as discussões ocorreram. Além disso, foram realizadas entrevistas com diferentes atores governamentais, do legislativo e da sociedade civil, entrevistas que foram fundamentais para compreender melhor a história contada nas atas e anais de encontros.

A escolha das regiões citadas teve por objetivo desenvolver uma análise exploratória de cada caso diante dos instrumentos legais existentes para interpretação da institucionalização das mesmas, tendo em vista que os determinantes legais estabelecidos em 1988 descaracterizam a funcionalidade das Regiões Metropolitanas (GARSON, 2009; SOUZA, 2004). Esta afirmação pode ser corroborada pelo fato de a maioria das constituições estaduais não estabelecerem mecanismos para efetiva existência de mecanismos ou estruturas institucionais de gestão metropolitana (GOUVÊA, 2005).

A maioria das constituições estaduais apenas reproduziu o texto da carta magna de 1988 sem que fosse especificado o processo de gestão. Tal fato pode ser interpretado como uma demonstração do desinteresse dos legisladores estaduais pela temática do arranjo metropolitano. Este cenário dificultou qualquer empreitada para a efetivação de um processo cooperativo a fim de estabelecer ações governamentais metropolitanas conjuntas. Mesmo sendo evidente a importância de ações conjuntas entre os entes federados, observa-se que a cooperação para a gestão metropolitana de fato não ocorre (GARSON, 2009).

A análise do processo constitutivo dos casos mostra que o marco constitucional federal representa um momento de mudança institucional e determinante condicional para a configuração do processo de 
gerenciamento das Regiões Metropolitanas, tendo como principal fator a relação conflituosa entre as partes constituintes da federação, diante da autonomia política, administrativa e legal concedidas. Em ambos os casos, observam-se conflitos de ação coletiva. Verifica-se a inexistência de iniciativas concretas entre os entes federativos visando à cooperação metropolitana. Isso permite inferir a necessidade de se construírem incentivos e mecanismos institucionais que proporcionem a cooperação intergovernamental voltada para a resolução de problemas comuns (OLSON, 1969, 1999; OSTROM, 1990, 2000, 2007).

O presente artigo está estruturado da seguinte forma: na seção 2, apresenta-se o enfoque teórico da perspectiva histórico-institucional de análise e a abordagem sobre os dilemas da ação coletiva; na seção 3 , será destacado o contexto metropolitano brasileiro; na quarta e quinta seções, serão apresentados os casos das RMs de Natal e Aracaju respectivamente; a última seção do texto será dedicada às considerações finais.

\section{A Perspectiva Histórico-institucional na Compreensão da Ação Coletiva e o Problema da Agregação Metropolitana}

A perspectiva analítica do institucionalismo histórico combina o método comparativo e o processo histórico de rastreamento de casos particulares, o que possibilita a absorção de um conjunto de preposições gerais sobre a maneira em que determinados objetos são afetados e como semelhantes ou diferentes resultados são apresentados em diferentes casos (trajetórias). De acordo com Thelen (1999), uma das reivindicações centrais do institucionalismo histórico é que as instituições representam mais do que um canal político e uma estrutura de conflitos. As instituições representam também a definição de interesses e objetivos criados em contextos institucionais - regras e rotas de políticas como inseparáveis entre si. Assim é que a perspectiva histórico-institucional tenta mostrar que as instituições possuem justaposições lógicas de ordem política a depender de sua base temporal. Os arranjos institucionais que compõem um sistema de governo surgem em momentos diferentes e fora de diferentes configurações históricas. Daí, na investigação orientada historicamente, tem-se uma preocupação com as origens e a trajetória, para a compreensão da evolução de um determinado modelo.

Nesse sentido, Pierson (2003), um dos principais autores que procura compreender o fenômeno da "Política no Tempo", destaca que um evento ou processo pode estar ligado crucialmente a processos subsequentes, mesmo que ocorra apenas uma vez e tenha deixado de ser operacionalizado muito antes da ocorrência do resultado final. Segundo o autor, tal como acontece com muitos processos de longo prazo, existem fortes razões teóricas para acreditar que o processo de path dependence seja predominante na vida política. Isto ocorre, pois , uma vez estabelecidos padrões específicos de mobilização política, as regras do jogo institucionalizadas, e até mesmo formas básicas de pensamento sobre o mundo político, geram a dinâmica de policy feedback. O argumento contido no conceito de policy feedback, para Thelen (1999), é que as instituições no bojo de seu processo de evolução, geram elementos que podem levar a baixos incentivos para a realização da ação coletiva. Nessa perspectiva, determinadas ações do processo decisório político também refletem para a trajetória dependente das instituições, tendo em vista que determinadas escolhas políticas podem manter a continuidade, reforçando a trajetória das instituições. Nesse sentido, Thelen (1999) apresenta que os mecanismos de feedback estão relacionados aos efeitos distributivos de instituições. A ideia é que as instituições não são neutras, mas são mecanismos de coordenação que refletem, reproduzem e ampliam padrões específicos de poder na política.

Assim, existe o argumento de que os arranjos institucionais afetam a capacidade de vários grupos de organizar e fazer alianças. A questão da formação de coalizões está relacionada à forma como os grupos interagem na política e na elaboração de políticas, sendo que as instituições afetam as possibilidades de diversos grupos em reconhecerem interesses comuns e constituírem alianças. As trajetórias dependentes das instituições são reflexos e produto das relações de poder e do contexto histórico em que estão envolvidas (THELEN, 1999). 
É importante a clareza com que os processos dinâmicos ajudam a explicar como padrões estáveis de política persistem e se reproduzem ao longo do tempo. No entanto, se faz necessário compreender os motivos que inserem as instituições em um contexto de constante mudança. As instituições evoluem e se modificam ao longo do tempo, existindo diferentes desdobramentos de processos em sua trajetória.

Neste trabalho, procurar-se-á observar este aspecto da teoria histórico-institucional contida no trabalho de Thelen (1999) - como o contexto e a trajetória são capazes de trazer incentivos negativos a um dado arranjo institucional. Ou seja, inserindo este elemento teórico como questão aqui do trabalho, busca-se aqui observar como arranjos institucionais desenhados para gerar uma ação de cooperação metropolitana, a partir da observação de dois casos - Aracaju e Sergipe, devido ao contexto onde estão imersos e à trajetória vista até aqui nas duas Regiões Metropolitanas, terminaram por criar incentivos negativos à cooperação metropolitana.

\section{O Problema da Cooperação na Trajetória das Instituições e na agregação metropolitana}

Em contextos de gestão metropolitana , observar-se-á o problema típico de ação coletiva, enunciado por Olson (1969, p. 47) - "The Fiscal Equivalence”, em que os governos municipais em áreas metropolitanas que constroem estradas vicinais ou realizam melhorias urbanas diversas com impacto para além de sua jurisdição o fazem em condições subótimas. Isso se deve ao fato de que o ônus tenderá a ser arcado pelos municípios maiores, ou pela cidade núcleo. Ou seja, na formação de arranjos metropolitanos, a capital ou município núcleo têm um papel central na organização propriamente dita da RM, e ao mesmo tempo é o município que mais "perderá", pois provavelmente dispensará mais recursos nos fundos e consórcios que a RM venha a constituir junto com os municípios médios e pequenos.

Para Ostrom (1990) , um problema de uso e produção de recursos comuns torna necessária a constituição de um sistema de normas estabelecidas pelos atores associados de forma a constituírem uma gestão coletiva. É importante aí analisar as instituições em seus aspectos de constituição normativa de forma a compreender o reconhecimento das regras estabelecidas, como também as constituídas por costumes que não são abordados pela legislação. Os contextos e trajetórias institucionais auxiliam na compreensão da legitimidade das normas entre os atores que compõem a ação coletiva. Segundo Ostrom (2000) , é preciso entender os contextos institucionais, culturais e biofísicos que afetam as ações coletivas e verificar as iniciativas políticas de incentivo à ação coletiva. Sendo necessário observar as competências e limitações existentes de forma a prover adequadamente um bem público (OLSON, 1969).

Neste trabalho será observado este aspecto, como o dilema Olsoniano, inerente das agregações metropolitanas versus a abordagem de Ostrom (1990), de tentativa de criação de um arranjo institucional que possa ser capaz de gerar um comportamento de cooperação intrametroplolitana. Será observado no trabalho que estes dois elementos auxiliam na análise histórica das duas regiões aqui em tela.

\section{Gestão Metropolitana no Brasil e sua Problemática Institucional}

A gestão metropolitana passa por uma redefinição de sua base institucional com as mudanças propostas para o sistema federativo brasileiro durante a elaboração da Constituição de 1988. A competência para criação e organização das Regiões Metropolitanas que antes era atribuição da União passou para os entes estaduais. Entretanto, a Constituição de 1988 também promoveu o município à condição de entidade federativa, o que diminuiu ou enterrou a legitimação dos entes estaduais na execução do papel de coordenador de ações metropolitanas (GARSON, 2009). 
Mesmo existindo a integração em um aglomerado único, tecido de relações e interações mútuas, Temer (2007) é enfático ao afirmar que a região metropolitana não é dotada de personalidade. Logo, mesmo na existência de transformações em um conjunto composto por um sistema socioeconômico relativamente autônomo, abrangendo as unidades integradas, segundo o autor, fica afastada a ideia de governo próprio, ou de até mesmo a Região Metropolitana (RM) possuir estrutura administrativa própria. Nessa perspectiva, a RM não pode ser considerada pessoa política, nem administrativa, nem centro personalizado ou organismo. Temer (2007) afirma que a Região Metropolitana é um órgão.

A natureza desse órgão será determinada por sua fonte criadora, que no caso em específico corresponde ao que estiver referenciado em lei complementar estadual, devendo-se observar que, mesmo que este órgão seja composto por Municípios, as decisões originárias da região metropolitana não obrigam que seus integrantes a cumpram, tendo em vista sua autonomia municipal. Temer (2007, p. 113) deixa claro que a interpretação da Constituição de 1988 evidencia que "a Região Metropolitana nada mais é do que órgão de planejamento, dele derivando a execução de funções públicas de interesse comum". O mesmo sendo aplicadas às outras configurações territoriais criadas pela Constituição de 1988, ou seja, às aglomerações urbanas e às microrregiões. Ressaltando que a relação entre os municípios ocorrerá através de convênio ou consórcio, constituídos de forma a viabilizar o seu funcionamento, somente pela adesão voluntária.

A fragilidade da base constitucional e o desinteresse político em relação à gestão metropolitana fazem com que os entes municipais se distanciem cada vez mais de uma ação conjunta efetiva. A compreensão do significado da competição entre unidades federativas acaba sendo interpretada de forma pejorativa e conduzindo os municípios a práticas predatórias como a prática de incentivos fiscais sem controle. Por meio de mecanismos de renúncia fiscal, cada município passa a ter suas cidades limítrofes como concorrentes a serem combatidos a qualquer custo, de forma a não observarem as vantagens na associação metropolitana (GOUVÊA, 2005).

Um dos fatores que respondem à ineficiência na realização de uma ação governamental conjunta para elaboração do planejamento metropolitano está fundamentado no princípio da autonomia municipal. O território municipal passou a ser um ambiente de concentração da maior parte do poder político local. Esta concentração de poder, associada aos interesses de determinados grupos pela legislação vigente em torno das vantagens obtidas pelo princípio da autonomia municipal, tornou inacessível o reconhecimento de que os municípios pertencentes às Regiões Metropolitanas devem ser observados de forma diferenciada dos demais.

O papel das RMs no sistema federativo brasileiro, perante suas relações governamentais, está atrelado à forma como a gestão destes territórios foi estabelecida, onde suas escolhas institucionais estão marcadas pela forte associação ao centralismo e autoritarismo do período militar. Com a trajetória marcada pela associação da gestão metropolitana ao período que foi inicialmente instituída, os constituintes apenas consideraram os fatos negativos sem observar variáveis importantes do sistema democrático, do sistema federativo e das relações governamentais. Com isso, durante o processo de redemocratização, as RMs perderam espaço na agenda política (SOUZA, 2004).

Devendo-se observar que a constituição dos arranjos institucionais metropolitanos simboliza contraposição ao processo de descentralização (GOUVÊA, 2005). Haja vista que a configuração destes arranjos gera algum nível de centralização no tocante aos processos decisórios envolvendo as ações governamentais metropolitanas. $\mathrm{O}$ que respalda na autonomia administrativa dos municípios integrantes de arranjos metropolitanos.

De acordo com Rolnik e Somekh (2004), mesmo que a constituição de um arranjo político-institucional metropolitano represente uma recentralização, isto não significa um retrocesso no processo democrático e de autonomia municipal. Deve ser compreendida como uma intervenção necessária à realidade socioeconômica 
apresentada pelo território metropolitano, que, por sua vez, depende de ações cooperativas, ao invés da proposta do individualismo localista.

No caso das RMs, faz-se necessária a existência de novos mecanismos de articulação que propiciem a interação entre as agências públicas de cada município integrante do território metropolitano. Mesmo cientes das tensões geradas pelas relações intergovernamentais, é preciso que se constitua um formato coeso de formulação e implementação de ações governamentais no âmbito metropolitano. Mesmo sob a égide da descentralização, as questões metropolitanas necessitam de soluções originárias e de um processo de gestão compartilhada entre os entes federados.

Por isso, Gouvêa (2005) relata a necessidade de existirem organismos voltados para realização de ações governamentais na dimensão metropolitana ou regional. Sendo importante a construção de uma institucionalidade metropolitana que observe as questões relacionadas às articulações políticas e técnicas, inserindo em seu contexto as formas de articulação e associações de interesses municipais existentes. Diante dos aspectos apresentados sobre a gestão metropolitana brasileira e sua formatação institucional, nas seções seguintes serão analisadas as RMs de Natal e Aracaju como forma de expor as problemáticas tanto para instituição das mesmas como para o processo de cooperação intergovernamental.

\section{Região Metropolitana de Natal}

O processo de institucionalização da RM de Natal pode ser estabelecido a partir do ano de 1977, através do Plano de Desenvolvimento Regional e Urbano da Grande Natal. Neste período, o governo do Estado do Rio Grande do Norte definia a Grande Natal como uma aglomeração urbana não metropolitana. Dentre as propostas estabelecidas pelo plano , era enfatizada a criação de um modelo institucional-administrativo capaz de subsidiar a operacionalização das premissas propostas voltadas para estruturação da Grande Natal como um único organismo.

O plano destacou premissas em relação ao quadro institucional, destacando que o quadro administrativo estadual na época não conduzia a região de forma prática ao desenvolvimento metropolitano. $\mathrm{O}$ relatório apresentou como proposta de institucionalização a criação de uma empresa pública ou de sociedade de economia mista, como forma de adequar os mecanismos de ação e controle. Deve-se ressaltar que a elaboração do plano ocorreu durante o período de Ditadura Militar de 1964. Posteriormente, em 1988 , foi elaborado um Plano de Estruturação do Aglomerado Urbano de Natal pelo escritório do ex-prefeito de Curitiba Jaime Lerner.

Em virtude da alteração constitucional federal de 1988, a Constituição do Rio Grande do Norte, assim como a de todas as unidades federativas brasileiras, passou a fazer menção à criação de RMs como competência estadual. Apenas duas passagens do texto constitucional do estado potiguar fazem referência à instituição de RMs. A primeira refere-se ao inciso terceiro do artigo 18, que é uma reprodução do parágrafo terceiro do artigo 25 da Constituição Federal de 1988. A segunda passagem torna a repetir a primeira passagem acrescentando incisos sobre incentivos para atividades econômicas agroindustriais.

Em 1995, foi encaminhada a proposta para criação da RM de Natal. Trata-se do projeto de Lei Complementar $\mathrm{n}^{\circ} 16$, cuja autoria foi da deputada estadual Fátima Bezerra, do Partido dos Trabalhadores (PT). Em sua propositura, a autora destaca como justificativa para instituição da lei a concentração das atividades industriais e comerciais no território metropolitano, sendo principalmente polarizadas no município de Natal.

A região, como de resto todo Estado, são, inequivocadamente, polarizados pelo município de Natal [...] A situação, preocupante, está a exigir dos poderes públicos a adoção de políticas e medidas que, a curto prazo, impeçam a sua acutização e, a médio e longo prazos, 
apontem para a solução o que, sua vez e, necessariamente, remete à ideia da gestão descentralizada do Estado. (BEZERRA, 1995, p. 5)

Conforme observado (sugestão: podemos observar) no trecho anterior, a justificativa faz referência à gestão descentralizada do Estado como forma de solução para as problemáticas evidenciadas no território metropolitano. A RM representaria a institucionalização da parceria do Governo do Estado com os chefes do executivo de cada município pertencente ao território delimitado. A descentralização da gestão proporcionaria maior agilidade nas ações públicas de interesse comum. Este arranjo institucional seria mais eficaz na solução de problemas comuns existentes no território metropolitano e redução nos custos envolvidos nas ações voltadas para a área.

[...] a propositura objetiva à descentralização de gestão do Estado e à consequente agilização nas decisões pertinentes às funções públicas de interesse coletivo, buscando solucionar, eficazmente, os problemas comuns à população residente na região. Simultaneamente, visa a uma maior racionalidade na aplicação dos recursos públicos. (BEZERRA, 1995, p. 5)

A autora destaca que os custos para implementação do conselho metropolitano não ocorrem pelo fato de ser aproveitada a estrutura administrativa e pessoal da Fundação Instituto de Desenvolvimento do Rio Grande do Norte (IDEC). O IDEC também seria um agente articulador entre os demais órgãos governamentais envolvidos nas ações do conselho e estruturação dos projetos voltados para o território metropolitano.

No parecer da Comissão de Constituição, Justiça e Redação sobre o projeto de Lei Complementar nº16/1995, foi constatada a inconstitucionalidade no fato de o projeto mencionar que a região metropolitana seria administrada por um Conselho Metropolitano. Este fato iria de encontro às competências resguardadas pela Constituição Federal aos Municípios, Estados e União, doravante a sua autonomia administrativa.

A comissão apresentou um texto substitutivo ao projeto original excluindo a atribuição administrativa do conselho metropolitano. Também foi modificada a composição do conselho, onde sua presidência passou a ser exercida pelo Secretário Estadual de Planejamento e Finanças, ao invés do Governador do Estado, mantendo-se o Conselho vinculado à secretaria citada anteriormente.

Dentre as atribuições estabelecidas pelo projeto lei, alterado pela comissão, o Conselho de Desenvolvimento Metropolitano de Natal tem como finalidade a promoção da integração e uniformização dos serviços comuns e de interesse da Região Metropolitana. Através da aplicação normativa, o conselho deve buscar a garantia da integração das ações voltadas para as funções e serviços públicos de interesse comum ao Estado e os municípios metropolitanos. Para tanto, conforme apresentado pelo projeto de lei complementar aprovado pela Assembleia Legislativa, o Conselho Metropolitano deve especificar as atribuições pertinentes a serem realizadas em parceria no âmbito metropolitano, diferenciando daquelas de interesse local.

O Conselho Metropolitano de Natal possui caráter normativo e deliberativo. A composição do conselho, segundo a lei aprovada, será de cinco membros escolhidos pelo Governador do Estado, a partir de uma lista tríplice organizada pelos prefeitos e suas respectivas câmaras municipais, sendo assegurada a participação da sociedade. A escolha dos membros deve ser pautada em suas capacidades técnica e/ou administrativa. Em relação aos recursos para a manutenção e funcionamento dos arranjos, ficou estabelecido que as despesas devem possuir dotações próprias nos orçamentos estadual e municipais.

O Projeto Lei Complementar $n^{\circ}$ 16/95, após aprovação legislativa , foi encaminhado para a sanção do poder executivo. No entanto, o governador Garibaldi Alves Filho, pertencente ao Partido do Movimento Democrático Brasileiro (PMDB), vetou integralmente. As razões para o veto consideraram a Lei Complementar estadual $n^{\circ}$ 119/94, que trata das definições dos princípios para regionalização do Estado do Rio Grande do Norte. Segundo a lei, a iniciativa para criação de RMs, aglomerados urbanos e microrregiões 
é de competência do chefe do poder executivo estadual. De acordo com o veto, o Projeto Lei Complementar no 16/95 não considerou os estabelecidos pela Lei Complementar estadual n 119/94.

Fixou-se, dessa forma, nesse dispositivo, a competência do Executivo para a iniciativa de lei destinada a promover a regionalização, dentro dos princípios definidos na citada Lei Complementar. Esses princípios, por sinal, não foram sequer levados em consideração no Projeto de Lei sob exame, o que demonstra, por si só, a necessidade de maior e melhor amadurecimento das medidas jurídicas e político-administrativas a serem propostas, para efeito de implementação de um projeto de criação de região metropolitana com características racionais e operacionais capazes de assegurar confiáveis chances de êxito. (VETO apud BEZERRA, 1995, p. 35)

A Assembleia Legislativa aprovou a Lei Complementar $n^{\circ}$ 152/1997, instituindo a Região Metropolitana de Natal e o Conselho Metropolitano. Apesar da criação do Conselho Metropolitano ter sido em 1997, a sua instalação ocorreu apenas em 2001, com a realização de cinco reuniões no período de doze meses compreendidos entre 2001 e 2002. Entre as questões abordadas estava a elaboração do estatuto e do regimento interno do Conselho Metropolitano.

Na ocasião da segunda instalação do Conselho Metropolitano para o período de 2005 a 2008, destaca-se a presença da governadora Wilma Maia (PSB), de sete prefeitos e dois representantes, além da vice-prefeita de Natal. Além do ato de posse, o Conselho Metropolitano realizou mais oito encontros. Segundo informações registradas em atas, as reuniões são marcadas pela discussão de temas pontuais e a ausência de representantes dos municípios, o que se constitui no enfraquecimento do Conselho.

Em 8 de dezembro de 2011, foi realizada uma audiência pública na Assembleia Legislativa. Na ocasião, o propositor da audiência, o deputado Hermano de Morais (PMDB) discorreu sobre o fato de o Governo do Estado não estar dando a devida importância para as questões metropolitanas, tendo em vista que o Conselho Metropolitano, que é presidido pelo secretário de planejamento do Estado, não realiza reuniões regulares. O fato de não existir uma participação mais efetiva no conselho dificulta a eleição de prioridades. Segundo Hermano Morais, os problemas são conhecidos por todos e não vêm recebendo a atenção devida do Estado que deve estar à frente da coordenação e direcionar as soluções.

O secretário adjunto da Secretaria de Planejamento, professor Lacerda, em seu pronunciamento na audiência pública assumiu o compromisso de que a primeira medida a ser realizada pela secretaria seria a reformatação do Conselho Metropolitano. E a segunda medida consistiria na atualização e discussão do Plano de Desenvolvimento Estratégico e Sustentável da RM de Natal. Segundo o secretário adjunto, existiria a possibilidade de firmar um convênio com a UFRN para o apoio acadêmico, tendo em vista subsidiar os trabalhos a serem realizados pela Coordenação da Região Metropolitana da Secretaria de Planejamento do Estado e pelo Conselho Metropolitano.

Entretanto, o deputado Fernando Mineiro (PT) enfatizou em seu pronunciamento que a mesma promessa de reformulação do conselho foi realizada em um evento do Parlamento Comum da Região Metropolitana em agosto de 2011, sendo necessário então estipular uma data para instalação do novo conselho. O deputado alega que não existem custos financeiros para ativar o Conselho Metropolitano, mas falta ação por parte do poder executivo estadual. Em seu relato, o deputado expõe que os problemas metropolitanos precisam entrar na agenda política, destacando à (a) imobilidade do governo estadual em relação à instalação do conselho metropolitano.

Com a formação da Frente Parlamentar dos deputados estaduais para debater as questões metropolitanas, no dia 26 de abril de 2012 foi realizado na Assembleia Legislativa um Seminário sobre a Gestão Metropolitana. Neste evento chegou-se à conclusão de que na região metropolitana de Natal não existe governança, sendo apontado o não funcionamento do Conselho Metropolitano como exemplo concreto. Destacou-se, ainda, que precisam ser criadas ferramentas para efetivação dos projetos que já foram desenvolvidos para o território 
metropolitano. Nos pronunciamentos dos deputados estaduais Hermano Morais e Fernando Mineiro, nota-se a questão da busca por uma gestão governamental e um estilo de governança adequados à realidade metropolitana, sendo necessárias a redefinição do modelo de gestão e uma institucionalidade para a RM de Natal.

Além de se verificar a ausência da construção dessa experiência a partir da ação espontânea dos atores, o que fortaleceria uma cultura metropolitana, houve, em sintonia com as preocupações de Thelen (1999), diferentes incongruências que se desenvolveram ao longo de todo o processo e que acabaram enfraquecendo a lógica de construção de um espaço de colaboração entre municípios e governo estadual. Rivalidades políticas, contradições de projetos e baixo envolvimento dos diversos atores são fatores que ajudam a entender a fragilidade desses espaços na produção de ação coletiva em busca da superação de problemas comuns. Ou seja, a experiência não foi capaz de construir ações coletivas.

\section{Região Metropolitana de Aracaju}

A instituição de regiões para fins de planejamento e gestão territorial integrada no Estado de Sergipe pode ser observada a partir da década de 1980. O governo de Augusto Prado Franco (PSDB), para atender às disposições sobre o parcelamento do solo urbano estabelecidos pela Lei Federal n ${ }^{\circ} 6766$ de 1979, declarou como área de interesse especial a região da Grande Aracaju. Instituída pela Lei Estadual no 2371 de 1982, a região da Grande Aracaju compreendia uma área territorial que abrangia sete municípios, dentre eles a capital sergipana.

Em 1990, o Governo do Estado de Sergipe, através da Secretaria de Estado de Economia e Finanças, apresentou um Plano de Desenvolvimento Urbano e Regional para a grande Aracaju. O projeto foi elaborado pelo escritório do urbanista Jaime Lerner com o intuito de traçar uma perspectiva para evolução da grande Aracaju para o ano 2000. O relatório final reúne as principais diretrizes relativas à Região da Grande Aracaju, destacando o seu crescimento demográfico e efeitos pelos investimentos industriais no território.

O relatório destaca a importância da institucionalização de um arranjo de gestão em nível estadual que coordene a gestão metropolitana que envolveria os municípios da Grande Aracaju e realça a necessidade de um plano diretor metropolitano. Na gestão, previa-se uma "estrutura composta por um Conselho de Desenvolvimento, que constituiria o fórum privilegiado de debates e de definição de políticas e por uma Secretaria Executiva" (SERGIPE, 1990, p. 3).

A Constituição Estadual de Sergipe faz referência à instituição de RMs em seu capítulo segundo, artigo 11, que trata das competências estaduais. Observa-se que o caput do artigo é uma cópia do artigo 25, parágrafo terceiro da Constituição Federal Brasileira.

Os três parágrafos do artigo 11 da Constituição Estadual Sergipana apresentam fatos relevantes em relação à criação das RMs. No parágrafo primeiro do artigo 11 é estabelecido que para a criação das RMs faz-se necessário a ratificação da lei pela câmara de vereadores dos municípios que formarão o território metropolitano. O parágrafo segundo do artigo 11 faz referência à possibilidade da criação de fundos municipais voltados para o desenvolvimento ou para execução das funções públicas de interesse comum.

O parágrafo terceiro estabelece os arranjos institucionais possíveis para a execução e o planejamento das funções públicas de interesse comum entre os entes municipais e o estadual. De acordo com o respectivo parágrafo, as funções poderão ser realizadas mediante concessão à entidade estadual ou municipal, podendo ser criada empresa de âmbito metropolitano ou através de convênios ou consórcios. Existindo também a permissão para a concessão à iniciativa privada de acordo com o estabelecido na forma da lei. 
A criação da Região Metropolitana de Aracaju foi instituída pela Lei Complementar 25 de 29 de dezembro de 1995. A lei foi sancionada na época pelo governador Albano Franco. A RM de Aracaju foi criada para realizar, de forma conjunta, as ações de organização, de planejamento e de execução de funções públicas de interesse comum. De acordo com a lei, os municípios de Aracaju, Barra dos Coqueiros, Nossa Senhora do Socorro e São Cristóvão compõem o território metropolitano, sendo que a capital do estado seria o município sede da RM.

A legislação destaca a garantia da participação popular nos organismos executores vinculados à estrutura de gestão da Região Metropolitana, por meio de suas instâncias representativas. Segundo a lei, a participação popular representa a garantia de controle das atividades realizadas no âmbito metropolitano, respaldado no pleno exercício da cidadania. Por fim, a lei complementar estabelece que um órgão colegiado deva ser criado para deliberar sobre ações comuns metropolitanas coordenadas pelo Estado.

A lei complementar que instituiu a RM foi originária da proposta do projeto do Deputado Estadual Ismael Silva, na época pertencente ao Partido dos Trabalhados. Ao propor o projeto , o deputado em sua justificativa traçou um panorama da realidade brasileira, destacando o crescimento urbano desordenado, a concentração das atividades econômicas e os principais problemas nas cidades.

O Deputado destaca na proposta de lei a garantia da autonomia municipal, diante da existência de normas gerais para o interesse comum. Enfatizando em suas palavras a dificuldade presente na administração das Regiões Metropolitanas.

Daí a necessidade de estabelecerem-se normas gerais, preservando a autonomia municipal na inter-relação de funções do interesse comum, que orientem o crescimento das cidades e instituam mecanismos para nortear a ação do Poder Público, com a efetiva participação da sociedade, em suas respectivas áreas de competências.[...] Admite-se por princípio, que administrar Regiões Metropolitanas não seja tarefa de fácil execução. O Projeto de Lei, ora apresentado [...] destina-se a criar a Região Metropolitana de Aracaju, de modo que a interação entre os [...] passem, harmonicamente, a ter os seus problemas comuns gerenciados. (SILVA, 1995 p. 11)

Na Comissão de Economia, Finanças e Orçamento, o relator deputado Bosco Costa (PSDB) salienta que a instituição das RMs como forma de integrar as ações públicas de interesse comum deve preservar a autonomia municipal. Segundo Bosco Costa (apud SILVA, 1995, p. 9), "se faz necessário estabelecer normas gerais, preservando a autonomia municipal na inter-relação coletiva aos objetivos que orientem o crescimento das cidades".

Na Comissão de Constituição e Justiça, o deputado relator Eduardo Marques (Partido da Frente Liberal PFL) apresentou voto favorável ao projeto de lei para criação da região metropolitana. De acordo com o relatório do deputado, outro projeto com objetivo idêntico apresentado pelo mesmo autor, no ano de 1991, fora rejeitado na mesma comissão. Segundo o deputado Eduardo Marques, o novo projeto buscou corrigir as falhas do anterior, sobretudo em não atingir a autonomia municipal, conforme enfatiza em dois trechos do seu relato.

Agora com a nova redação, o autor procurou corrigir [...] o projeto anterior, adequando a realidade das Constituições Federal e Estadual, e não ferindo a autonomia municipal, princípio que por todos deve ser altamente respeitado. [...] Reconhecemos [...] da necessidade de um planejamento intermunicipal, tal o crescimento desordenado das cidades, e a interferência não apenas no aspecto físico-territorial, mas também nos prismas socioeconômicos, mas jamais sem deixar de enfocar e resguardar a autonomia municipal, como unidade administrativa e célula primeira do sistema federativo, o que vemos que houve avanço com relação ao projeto original [...] (MARQUES apud SILVA, 1995, p. 6) 
Mesmo diante do reconhecimento por parte da relatoria da necessidade da existência do planejamento intermunicipal, as passagens citadas acima deixam evidente a questão da preservação da autonomia municipal. O avanço indicado pelo deputado Eduardo Marques consiste na redação atribuída pelo caput do artigo quinto do projeto de lei, conforme relata:

\begin{abstract}
"A adesão do município à Região Metropolitana deverá ser ratificada pela Câmara dos Vereadores de cada município" (grifo nosso). Portanto não à obrigatoriedade do município na participação da Região Metropolitana, ele só se incorpora à mesma, se seus dignos representantes (Câmara de Vereadores), quando consultados, ratificaram a consulta, se manifestando favoravelmente. (MARQUES apud SILVA, 1995, p. 6)
\end{abstract}

Ao finalizar seu relato sobre o projeto, o deputado destaca que os aspectos novos deram novo enfoque à matéria possibilitando a continuidade da tramitação do processo. Ressalta que devido à complexidade da matéria, que divide a opinião dos doutrinadores e tratadistas, fazem-se necessários reparos no projeto de lei para criação da região metropolitana de Aracaju.

Ao regulamentar a Região, a cautela e a prudência devem ser a tônica a prosseguir, o fixar limites claros e precisos, entre o que é interesse municipal e interesse de todos os municípios envolvidos na área metropolitana, para que realmente sejam encontradas soluções legítimas, justas e equitativas, respeitando-se as peculiaridades locais e identidade. (MARQUES apud SILVA, 1995, p. 7)

Diante do exposto pelo relato do deputado Eduardo Marques, fez-se necessário proceder à análise do projeto de Lei número 77 de 1991, elaborado pelo então deputado Ismael Silva, com o intuito de verificar as diferenças entre os projetos. A primeira evidência apontada é que o projeto de lei $\mathrm{n}^{\circ} 77$ de 1991 buscava estabelecer as diretrizes gerais para a instituição de RMs e aglomerações urbanas no território do estado de Sergipe. Já o projeto de lei complementar no 8 de 1995 tratava sobre a criação da Região Metropolitana de Aracaju.

Destaca-se no projeto de lei $\mathrm{n}^{\circ} 77$ de 1991 que no arranjo institucional apresentado existia a figura de um prefeito do município da sede metropolitana, sendo apoiado por um Conselho Deliberativo, onde os integrantes seriam eleitos pelos municípios da região metropolitana. Os recursos a serem utilizados para manutenção do arranjo institucional seriam rateados proporcionalmente entre os municípios integrantes. A adesão e a saída do município aconteceriam com pelo menos dois terços dos votos da Câmara de Vereadores de cada município.

Art.4: As ações comuns da Região Metropolitana serão coordenadas pelo prefeito do Município da Sede Metropolitana, apoiado em resolução do Conselho Deliberativo, composto, proporcionalmente, às suas representações nas Câmaras Municipais, por conselheiros eleitos pelos municípios componentes.

Parágrafo Único: As resoluções do Conselho Deliberativo serão respeitadas pelas unidades agregadas, no âmbito de ações das organizações supra municipais (SILVA, 1991, p. 3)

O deputado relator do projeto de lei no 77 de 1991, Djenal Queiroz (Partido Social Democrático - PDS), na Comissão de Constituição e Justiça, afirma que o artigo quarto e seu parágrafo único ferem a constituição federal, ao não respeitar o princípio da autonomia municipal, destacando que o próprio autor do projeto relata em sua justificativa a preservação da autonomia municipal ao serem estabelecidas as normas gerais para as ações de interesse comum entre os municípios da região metropolitana.

Sem que haja a necessidade do emprego de recursos técnicos de hermenêutica ou de interpretação da lei, ou melhor, logo à primeira vista, percebe-se, sem qualquer dificuldade, que o disposto, globalmente, [...], colide frontalmente com as Constituições Federal e 


\begin{abstract}
Estadual, à medida em que na medida em que fere o consagrado princípio Constitucional da autonomia municipal, ao possibilitar que a Região Metropolitana extrapole as suas funções, [...] que a instituição da Região Metropolitana se transforme na instituição de uma organização supra municipal, cujas decisões terão que ser respeitadas pelos municípios agregados, desde que baseados em deliberações do mencionado Conselho Deliberativo, constituído de conselheiros que não serão os Prefeitos e nem os membros das Câmaras dos Vereadores dos respectivos municípios, os quais são os legítimos representantes do povo, na consagrada forma constitucional. (QUEIROZ apud SILVA, 1991, p. 19-20)
\end{abstract}

O relator destaca o fato de não existirem critérios para indicação do município sede e a forma como são escolhidos os membros do Conselho Deliberativo. O deputado Djenal Queiroz enfatiza que o interesse metropolitano deve assegurar a legitimidade dos municípios e respeitar sua competência de autogoverno. Os pontos levantados pelo relator refletem um cenário que contrariam normas e regras constitucionais, sendo enfatizado principalmente o princípio da autonomia municipal. Estes fatores conduziram ao parecer contrário à aprovação do projeto de lei $\mathrm{n}^{\circ} 77$ de 1991. Observa-se que, em ambos os projetos apresentados pelo deputado Ismael Silva, a questão da autonomia municipal foi um fator preponderante para a reprovação do primeiro projeto e a aprovação do segundo.

Em 2003, através da sanção da Lei Complementar nº6 pelo Governador João Alves Filho (PFL), surge a figura do Conselho de Desenvolvimento da Região Metropolitana de Aracaju (CONDEMETRO), instituído pela Lei $\mathrm{n}^{\circ} 5355$ de 2004. O CONDEMETRO é criado na condição de órgão colegiado de caráter deliberativo, com função normativa. A primeira competência do CONDEMETRO consistia em aprovar a implantação da Região Metropolitana de Aracaju. Fato não evidenciado até o presente momento.

Após a sanção da lei que dispõe sobre a instituição do CONDEMETRO, o governo do estado sancionou a Lei $\mathrm{n}^{\circ} 5375$ de 2004 , que cria as regiões de planejamento. Dentre os seis territórios criados, encontra-se a região intitulada de 'Grande Aracaju', formada pelos municípios de Aracaju, Barra dos Coqueiros, Nossa Senhora do Socorro e São Cristóvão. Observa-se que correspondem aos mesmos municípios que compõem a Região Metropolitana de Aracaju.

Em 2005, foi criada através da Lei $n^{\circ} 5656$ a Secretaria de Estado de Integração de Serviços Públicos Metropolitanos (SECMETRO). A finalidade da Secretaria consistia no desenvolvimento das funções governamentais referentes à integração de serviços públicos metropolitanos. A secretaria proporcionava também a assistência e o relacionamento entre as administrações públicas dos municípios que constituem a região metropolitana.

Com a mudança de governo ocorrida no ano de 2007 (Governador Marcelo Déda - PT), após 18 meses de instituída, a SECMETRO foi extinta pela reforma administrativa prevista na Lei $\mathrm{n}^{\circ} 6.130$, de 02 de abril de 2007, e a CONDEMETRO passou a ser um órgão vinculado à recém-criada Secretaria de Transportes e Integração Metropolitana (SETRAN). Segundo a Lei $n^{\circ}$ 6.344/2008, que dispõe sobre a organização básica da secretaria, a SETRAN é um órgão de natureza operacional voltado para as atividades políticas de transporte, trânsito e integração dos serviços públicos metropolitanos.

No ano de 2007, o Governo do Estado também instituiu pelo Decreto no 24338/2007 os territórios de planejamento do Estado de Sergipe. De acordo com o decreto, o Estado de Sergipe foi dividido em oito territórios, sendo um deles denominado de Grande Aracaju e formado por nove municípios incluindo a Região Metropolitana de Aracaju.

A SETRAN foi extinta pela Lei $\mathrm{n}^{\circ}$ 6.615, de 18 de junho de 2009, e suas atribuições passaram a ser desenvolvidas pela Secretaria de Estado da Infraestrutura (SEINFRA). A lei não expressa o destino do CONDEMETRO, o que conduz a uma interpretação por analogia, onde se subtende que o órgão deliberativo da Região Metropolitana de Aracaju esteja vinculado a SEINFRA. 
Desde 1995, a Região Metropolitana de Aracaju encontra-se legalmente instituída, sendo seu órgão colegiado, o CONDEMETRO, criado em 2003. No entanto, o arranjo metropolitano está presente apenas no texto de lei. Neste aspecto, a Região Metropolitana de Aracaju fica impossibilitada de ratificar qualquer projeto, devido o não funcionamento de seu órgão colegiado. Em termos normativos, a Região Metropolitana volta a ser citada apenas na Lei $\mathrm{n}^{\circ} 7116$ de 2011, com a instituição da Secretaria de Estado de Desenvolvimento Urbano. É competência da Secretaria a coordenação e auxílio no desenvolvimento das ações de interesse das Regiões Metropolitanas. Entretanto, a lei não apresenta a CONDEMETRO como órgão vinculado a sua estrutura organizacional.

O caso da RM Aracaju, assim como visto da Região Metropolitana de Natal, permite verificar que a inexistência de mecanismos de incentivos institucionais que proporcionem a cooperação intergovernamental foi um dos fatores centrais que não permitiram que a ação conjunta ocorresse em bases concretas voltadas para o interesse comum (OLSON, 1969, 1999; OSTROM, 1990, 2000, 2007). Criou-se um órgão colegiado, o CONDEMETRO, que na prática existe apenas no papel uma vez que atores políticos centrais nesse processo (prefeituras e governo do estado) não fizeram o esforço adequado para que a gestão metropolitana se materializasse com base em políticas públicas comuns ao novo território. Pelo contrário, cada município continuou olhando, apenas, para as suas questões.

\section{Considerações Finais}

A abordagem do institucionalismo histórico auxiliou no sentido de fornecer pistas para buscar compreender as razões do fracasso da gestão metropolitana nos casos aqui estudados. Thelen (1999), ao afirmar que instituições representam para além de canal político e estrutura de resolução de conflitos, espaços de definição de interesses e objetivos, demonstra que esses espaços de gestão formados pelos municípios não foram capazes de transformar interesses individuais (dos municípios) em ações coletivas (metropolitanas) dado, sobretudo, a tradição brasileira de se pensar problemas dentro da lógica do território municipal. Aqui também se fazem presentes elementos de Pierson quando se leva em consideração a trajetória brasileira de não lidar mais objetivamente com espaços de cooperação intergovernamental.

Como diz Ostrom (2000), numa ação coletiva é preciso demonstrar as vantagens que a ação conjunta pode trazer. Nos dois casos em questão, os cenários construídos desde a concepção das duas RMs até a tentativa de construção de mecanismos concretos de gestão não deixaram claro que o custo de abrir mão da autonomia individual em determinados contextos seria compensador. Ou seja, o espírito colaborativo que orientaria as ações metropolitanas não foi desenvolvido, ou assimilado, pelos diferentes agentes. Ou seja, nos dois casos, as RMs não se configuraram como instituição. Ou, como diria Putnam (2006), os agentes cooperariam, caso fossem capazes de perceber que a ação conjunta é efetivamente a melhor vantagem para todos que formam o grupo.

É preciso lembrar que arranjos institucionais afetam a capacidade de vários grupos de organizar e fazer alianças. Nos dois casos em questão, como os arranjos institucionais foram frágeis e não se efetivou como espaço de produção e gestão de políticas públicas de cooperação, é compreensível o fracasso dessas experiências. Também é importante lembrar que estamos falando de relações e alianças políticas que muitas vezes colocam em confronto projetos de poder de partidos e pessoas, o que tem um alto potencial para provocar conflitos e não cooperação.

A pesquisa realizada mostra que a gestão metropolitana ocorrerá quando existir de fato maior interesse por parte dos entes federados envolvidos, principalmente do governo estadual. A análise das RMs de Natal e Aracaju permite evidenciar que os mecanismos institucionais existentes não são suficientes para fomentar o interesse pela gestão metropolitana. Mesmo diante da existência legal, os casos analisados não apresentam efetivamente uma condução territorial compartilhada. 
Em ambos os casos as proposituras de lei complementar para criação das RMs de Natal e Aracaju foram de autoria de deputados estaduais do Partido dos Trabalhadores. Mesmo na condição de oposição aos governos estaduais no período 1995 a 1998, as propostas para criação das Regiões Metropolitanas foram aprovadas com modificações em seus textos. As tramitações dos processos para criação das RMs estudadas evidenciam a preocupação em torno da autonomia municipal.

O fato de as leis complementares estabelecerem o ente estadual como responsável pela coordenação das RMs não garantiu a existência de uma efetiva gestão metropolitana alicerçada na cooperação. Em ambos os casos é evidenciada a existência de planos para os territórios, anteriores às leis complementares, elaborados pelos governos estaduais. Entretanto, com a instituição dos Conselhos Metropolitanos, o fato observado é o desinteresse do poder executivo pela atuação do órgão colegiado.

Um ponto a ser destacado é a sobreposição de órgãos com a mesma função. Apesar da configuração dos conselhos metropolitanos, os entes estaduais constituíram outros órgãos para tratar das questões metropolitanas. O que fortalece a premissa em relação ao desinteresse estadual em atuar de forma cooperada com os municípios que compõem a região metropolitana através dos conselhos.

Diante do exposto, pode-se evidenciar que a gestão compartilhada nas RMs de Natal e Aracaju não ocorre devido à inexistência de um objetivo comum que sobressaia aos interesses políticos e de rent-seeking de cada ente federado. Sendo necessário rever as normas institucionais existentes para cada região metropolitana com o intuito de fomentar a gestão metropolitana. Devendo-se considerar critérios técnicos para estabelecer os municípios que de fato apresentam características metropolitanas e definir os membros dos conselhos.

A gestão metropolitana ocorrerá, caso exista um maior interesse do ente estadual e um interesse conjunto dos municípios que compõem cada território metropolitano, sendo liderados pelo município sede. O interesse estadual é justificado pelo fato de o mesmo ser o responsável pela condução do conselho metropolitano e possuir maiores condições orçamentárias para fomentar a cooperação metropolitana. Isso é importante, pois leva em consideração a abordagem de Olson (1969) da equivalência fiscal, dado que é o Governo Estadual quem poderá "arbitrar" o papel de cada município na respectiva Região Metropolitana e, evidentemente aí, o papel do município sede, a capital, que será a maior "provedora" de recursos e devido a isso, dada a sua concentração política e econômica, caberia ao município sede o papel de liderar o grupo metropolitano em favor de uma maior cooperação intrametropolitana. Sem a presença do ente estadual , a possibilidade para a atuação do conselho metropolitano recai no interesse de cada município em efetivar a cooperação pela gestão metropolitana.

Dado isso, é que se observa a necessidade da criação de um marco legal acerca da gestão metropolitana no país. Neste sentido, está em trâmite no Congresso Nacional o Estatuto da Metrópole - Projeto de Lei ${ }^{\circ}$ 3460/2004, que se encontra no momento em elaboração de parecer final em Comissão Especial.

O desafio a ser alcançado é a constituição de um arranjo institucional que possibilite a legitimidade necessária para a existência da gestão metropolitana. Para tanto , se faz necessária uma maior exploração empírica das demais RMs que surgiram após a Constituição de 1988, buscando observar se a motivação política, conforme constatado nas RMs de Natal e Aracaju, é o principal fator para a instituição dos seus territórios metropolitanos, diante da fragilidade do arcabouço institucional existente. 


\section{Referências}

BEZERRA, F. Projeto de Lei Complementar no 16 de 22 de junho de 1995. Institui a região metropolitana de Natal e dá outras providências. Natal, RN, 1995. 61 p.

GARSON, S. Regiões Metropolitanas: por que não cooperam? Rio de Janeiro: Letra Capital: Observatório das Metrópoles. Belo Horizonte, MG: PUC, 2009.

GOUVÊA, R. G. A questão metropolitana no Brasil. Rio de Janeiro: Editora FGV, 2005.

NORTH, D. C. Institutions, Institutional Change and Economic Performance. Cambridge: Cambridge University Press, 1990.

OLSON, M. The Principle of "Fiscal Equivalence": The Division of Responsibilities among Different Levels of Government. The American Economic Review, v. 59, n. 2, p. 479-487, May, 1969.

A lógica da ação coletiva: os benefícios públicos e uma teoria dos grupos sociais. São Paulo: Editora da Universidade de São Paulo, 1999.

OSTROM, E. Governing the Commons: The Evolution of Institutions for Collective Active. New York: Cambridge University Press, 1990.

Collective Action and the Evolution of Social Norms, Source. The Journal of Economic Perspectives, v. 14, n. 3, p. 137-158, 2000.

Collective action theory. In: BOX, C.; STOKES, S. C. The Oxford handbook of comparative politics. New York: Oxford University Press Inc., 2007.

PIERSON, P. Big, Slow-moving, and invisible: macrossocial processes in the study of comparative politics. In: MANONEY, J.; RUESCHEMEYER, D. Comparative historical analysis in the social sciences. UK: Cambridge University Press, 2003.

PUTNAM, R. D. Comunidade e democracia: a experiência da Itália moderna. 5. ed. Rio de Janeiro: Editora FGV, 2006.

ROLNIK, R.; SOMEKH, N. Governar as metrópoles: dilemas da recentralização. In: RIBEIRO, L. C. Q. (Org.). Metrópoles: entre a coesão e a fragmentação, a cooperação e o conflito. São Paulo: Editora Fundação Perseu Abramo; Rio de Janeiro: FASE, 2004.

SERGIPE. Secretaria de Estado de Economia e de Finanças. Grande Aracaju Ano 2000: Plano de Desenvolvimento Urbano e Regional. Aracaju/SE, junho de 1990, 180p.

SILVA, I. Projeto de Lei Complementar $n^{\circ} 77$ de 28 de maio de 1991. Estabelece as diretrizes gerais para a instituição de regiões metropolitanas e aglomerações urbanas no território do Estado de Sergipe. Aracaju, SE, 1991. 21 p.

Projeto de Lei Complementar n⿳8 de 24 de outubro de 1995. Cria a região metropolitana de Aracaju e dá outras providências. Aracaju, SE, 1995. 14 p.

SOUZA, C. Regiões Metropolitanas: trajetória e influência das escolhas institucionais. In: RIBEIRO, L. C. Q. (Org.). Metrópoles: entre a coesão e a fragmentação, a cooperação e o conflito. São Paulo: Editora Fundação Perseu Abramo; Rio de Janeiro: FASE, 2004.

TEMER, M. Elementos de direito constitucional. 22 ed. São Paulo: Malheiros Editores Ltda, 2007.

THELEN, K. Historical institutionalism and comparative politics. Annual Review of Political Science, v. 2, p. 369404, 1999.

WILLIAMSON, O. The mechanism of governance. Nova York: Oxford University Press, 1996. 